\title{
Predictive factors of proximal advanced neoplasia in the large bowel
}

\author{
Miroslaw Kiedrowski ${ }^{1,2}$, Andrzej Mroz ${ }^{1,2}$, Michal F. Kaminski ${ }^{3}$, Ewa Kraszewska ${ }^{1}$, Janina Orlowska², \\ Jaroslaw Regula1,3
}

\begin{abstract}
${ }^{1}$ Department of Gastroenterology and Hepatology, Medical Center for Postgraduate Education, Warsaw, Poland

${ }^{2}$ Department of Pathology, Maria Sklodowska-Curie Memorial Cancer Center and Institute of Oncology, Warsaw, Poland

${ }^{3}$ Department of Gastroenterology, Maria Sklodowska-Curie Memorial Cancer Center and Institute of Oncology, Warsaw, Poland
\end{abstract}

Submitted: 4 February 2013

Accepted: 23 June 2013

Arch Med Sci 2014; 10, 3: 484-489

DOI: 10.5114 /aoms.2013.38394

Copyright @ 2014 Termedia \& Banach

\section{Abstract}

Introduction: The aim of the study was to evaluate the impact of sex, age, family history and distal findings on the risk of proximal advanced neoplasia (cancer or advanced adenoma) in the large bowel.

Material and methods: Records for 10111 asymptomatic participants of the Colonoscopy Screening Program (CSP), recruited from the Warsaw region between 2000 and 2004, were analyzed. A multivariate logistic regression model was used to estimate the impact of sex, age, family history and most advanced distal lesions on the occurrence of proximal advanced neoplasia. To enhance comparability of the study two definitions of the proximal colon were applied - either the splenic flexure $\left(1^{\text {st }}\right)$ or the bend between the descending and sigmoid colon ( $2^{\text {nd }}$ definition) represented the boundary.

Results: One hundred and thirty-three $\left(1^{\text {st }}\right)$ and 167 patients ( ${ }^{\text {nd }}$ definition) were found to have at least one advanced neoplastic lesion in the proximal part, respectively. Eleven and 14 patients were found to have carcinoma, while in 130 and 163 patients at least one proximal advanced adenoma appeared. Men were at twice as high risk of having advanced neoplasia in the proximal colon than women $(\mathrm{OR}=1.94,95 \% \mathrm{Cl}: 1.31-2.87, p=0.001$ or $\mathrm{OR}=1.69,95 \% \mathrm{Cl}: 1.20-2.40, p=0.003$, respectively). The presence of distal advanced neoplastic lesions was associated with 3.5 times higher risk of proximal advanced neoplasia $(\mathrm{OR}=3.58,95 \% \mathrm{Cl}: 2.00-6.43, p<0.0001$ or $\mathrm{OR}=3.41,95 \% \mathrm{Cl}: 1.95-5.96, p<0.0001)$, respectively.

Conclusions: The results may confirm some limitation of flexible sigmoidoscopy in the screening settings in comparison with colonoscopy, at least in men and people with distal advanced neoplasia.

Key words: colonoscopy, colorectal cancer, neoplasia, flexible sigmoidoscopy, screening.

\section{Introduction}

Colorectal carcinoma (CRC) in Western societies is the second cause of cancer-related mortality with the perspective of a growing impact on national health care systems. Also in Poland it is a significant problem and a disturbing increase in the CRC incidence has been observed in

\author{
Corresponding author: \\ Miroslaw Kiedrowski MD, \\ PhD \\ Department \\ of Gastroenterology \\ and Hepatology \\ Medical Center \\ for Postgraduate Education \\ 5 W.K. Roentgena St \\ 02-781 Warsaw, Poland \\ Phone: +48 225463044 \\ E-mail: mkiedrow@mp.pl
}


recent years [1]. Colorectal carcinoma is, however, preventable, as most of the sporadic cases develop from their premalignant counterparts. In 1 of 5 to 6 asymptomatic participants of the screening program at least one adenoma is detected [2]. Some adenomas are proved to have a significantly higher potential of malignant progression. Being the direct precursors of CRC they are recognized as advanced adenomas (AA). Advanced adenomas are defined as lesions of at least $10 \mathrm{~mm}$ in diameter, with high-grade neoplasia, villous or tubulo-villous morphology, or any combination of the above features [3]. Colorectal carcinomas and their direct precursors - advanced adenomas - require urgent management and are defined as advanced neoplastic lesions according to their histological and clinical features. Early endoscopic detection and removal of advanced neoplastic lesions decreases cancer related mortality. Consequently endoscopic screening has been introduced to preventive strategy practices [4-7]. Full length bowel inspection (colonoscopy - CS) and flexible sigmoidoscopy (FSS) are advocated in official recommendations [8]. Advantages and drawbacks of both methods warrant their comparison in the colorectal screening settings. The simplicity, comfort and safety of FSS must be balanced with expected effectiveness, which is impaired by the $60 \mathrm{~cm}$ range of inspection. Such restriction leads to misdetection of a substantial number of advanced neoplastic lesions [9]. Furthermore, additional doubts appear due to the postulated proximal shift of colorectal cancers and advanced adenomas - fortunately both of them seem to be illusive [10, 11]. Several authors have reported that the presence of distal epithelial polyps may predict the occurrence of proximal lesions $[12,13]$. Therefore distal lesions along with certain clinical features could serve as useful indicators of people who would benefit most from full CS, while the rest of screened people would benefit sufficiently from FSS.

It is worth noting that dual designations of the proximal segment in the large bowel are used in the literature. The first approach relies on diverse embryological origin of the proximal and distal parts, as well as the topography of the mesocolon. In this designation the splenic flexure constitutes the boundary; the proximal (or right) part consists of the cecum, ascending colon, hepatic flexure, transverse colon and the splenic flexure itself. The second definition corresponds to the extent of the flexible endoscope. In this approach the boundary between the proximal and distal part is the bend between the descending and sigmoid colon. Both approaches were utilized in our analysis to enhance comparability.

\section{Material and methods}

Records for 10111 asymptomatic participants of the National Colorectal Cancer Screening Program (CSP) from the Warsaw region who underwent colonoscopy between 2000 and 2004 were analyzed. They were people 50-65 years old, regardless of their family history, as well as people 40-65 years old with a first line relative diagnosed with CRC [14]. The demographic description of the study group is presented in Table I.

Clinical data were collected, including sex, age and family history. Detailed histopathologic analysis was performed, using the WHO classification [15]. Each epithelial lesion was described in terms of size, localization, histology, presence and grade of intraepithelial neoplasia (when applicable). Only full colonoscopies (cecum reached) were analyzed to minimize the possibility of not detecting clinically relevant proximal lesions.

The following factors were considered as possible predictors of proximal advanced neoplasia:

Table I. Characteristics of participants of the Colonoscopy Screening Program

\begin{tabular}{|c|c|c|c|}
\hline Parameter & & Results & \\
\hline Mean age, mean \pm SD & & $55.53 \pm 5.70$ & \\
\hline \multicolumn{4}{|l|}{ Gender, $n(\%)$ : } \\
\hline Male & & $3452(34.14)$ & \\
\hline Female & & $6659(65.86)$ & \\
\hline \multicolumn{4}{|l|}{ Age group [years]: } \\
\hline$\leq 45$ & $522(5.16 \%)$ & M: 200 & F: 322 \\
\hline $46-50$ & $1276(12.62 \%)$ & M: 422 & F: 854 \\
\hline $51-55$ & 3337 (33.00\%) & M: 1108 & F: 2229 \\
\hline $56-60$ & $2661(26.32 \%)$ & M: 892 & F: 1769 \\
\hline$\geq 61$ & $2315(22.90 \%)$ & M: 810 & F: 1505 \\
\hline
\end{tabular}


Table II. Histological description of advanced neoplastic lesions

\begin{tabular}{|c|c|c|c|}
\hline Variable & $\begin{array}{l}\text { Number } \\
\text { of lesions }\end{array}$ & $\begin{array}{c}\text { Dysplasia } \\
\text { (if appli- } \\
\text { cable) }\end{array}$ & Size \\
\hline Cancers & 53 & & $\begin{array}{c}\geq 10 \mathrm{~mm} ; n=52 \\
<10 \mathrm{~mm} ; n=1\end{array}$ \\
\hline $\begin{array}{l}\text { Advanced } \\
\text { adenomas: }\end{array}$ & 490 & $\begin{array}{l}432 \text { LGD } \\
58 \text { HGD }\end{array}$ & $\begin{array}{l}\geq 10 \mathrm{~mm} ; n=264 \\
<10 \mathrm{~mm}: n=226\end{array}$ \\
\hline Tubular & 170 & $\begin{array}{l}127 \text { LGD } \\
43 \mathrm{HGD}\end{array}$ & $\begin{array}{l}\geq 10 \mathrm{~mm} ; n=147 \\
<10 \mathrm{~mm} ; n=23\end{array}$ \\
\hline $\begin{array}{l}\text { Tubulo- } \\
\text { villous }\end{array}$ & 285 & $\begin{array}{l}271 \text { LGD } \\
14 \mathrm{HGD}\end{array}$ & $\begin{array}{l}\geq 10 \mathrm{~mm} ; n=94 \\
<10 \mathrm{~mm} ; n=191\end{array}$ \\
\hline $\begin{array}{l}\text { Villous } \\
\text { adenoma }\end{array}$ & 17 & 17 LGD & $<10 \mathrm{~mm} ; n=17$ \\
\hline $\begin{array}{l}\text { Serrated } \\
\text { adenoma }\end{array}$ & 18 & $\begin{array}{l}17 \text { LGD } \\
1 \mathrm{HGD}\end{array}$ & $>10 \mathrm{~mm} ; n=18$ \\
\hline Total & 543 & & \\
\hline
\end{tabular}

gender, age $(<45,46-50,51-55,56-60)$, family history (not shown) and the most advanced distal lesion (MADL). Most advanced distal lesion parameters were categorized as:

- lack of distal abnormalities,

- presence of at least one hyperplastic polyp,

- presence of at least one non-advanced adenoma,

- presence of at least one advanced neoplastic lesion.

\section{Statistical analysis}

In the case of multiple lesions the more advanced category was assigned for the MADL. Presence of at least one advanced neoplastic lesion in the proximal colon was the primary endpoint of the study. The association between considered risk factors and presence of proximal advanced neoplasia was assessed using multiple logistic regression models. The models were fitted using Hosmer-Lemeshow statistics. Five percent level of significance was used. All tests were two-sided and the analysis was performed for two definitions of proximality.

\section{Results}

Two thousand and seven participants were found to have 3248 adenomas of any type (tubular, tubulo-villous, villous and/or serrated). Four hundred and seventy participants were found to have 543 advanced neoplastic lesions - carcinomas and advanced adenomas altogether. The histological description of the advanced neoplastic lesions is presented in Table II.

Fifty-three patients were found to have cancer - most of them in the distal part of the colon. In $11\left(1^{\text {st }}\right)$ and $14\left(2^{\text {nd }}\right.$ definition of proximal seg- ment) participants the carcinoma was located in the proximal portion. No patients with synchronous carcinomas were found.

Four hundred and ninety advanced adenomas were found in 424 patients. Three hundred and seventy-seven participants were found to have $1 \mathrm{AA}$, while the rest were found to have multiple polyps. In 123 (154) people AA were located in the proximal part (respectively).

Overall 133 and 167 patients with at least one advanced proximal neoplastic lesion were identified for the $1^{\text {st }}$ and $2^{\text {nd }}$ definitions of proximality, respectively. The anatomical distribution of advanced neoplastic lesions - carcinomas and AA is presented in Table III.

Among 353 patients with distal advanced neoplasia (carcinoma and/or AA) 17 participants $(4.82 \%)$ were found to have at least one proximal $\mathrm{AA}$ and/or carcinoma ( $1^{\text {st }}$ definition of proximal portion). For the $2^{\text {nd }}$ definition 18 participants out of 320 (5.63\%) were identified with such coexistence.

The risk factors of proximal advanced neoplastic lesion(s) are presented in Table IV. Presence of advanced distal neoplastic lesions was one of the reliable predictors of proximal advanced neoplasia. The risk was increased by about 3.5 times, irrespectively of proximality definition, and highly significant $(\mathrm{OR}=3.58,95 \% \mathrm{Cl}: 2.00-6.43, p<0.0001$; $\mathrm{OR}=3.41,95 \% \mathrm{Cl}: 1.95-5.96, p<0.0001$; respectively). Furthermore, males were more prone to have advanced proximal neoplasia $(\mathrm{OR}=1.94$, 95\% Cl: 1.31-2.87, $p=0.001 ; \mathrm{OR}=1.69,95 \% \mathrm{Cl}$ : $1.20-2.40, p=0.003$; respectively).

\section{Discussion}

In the colorectal screening settings the efficacy, safety, accessibility and financing issues have to be balanced. The optimal approach may face obvious limitations in lesion detection rate for the price of fitting to the system requirements. Accordingly several screening methods are available, namely fecal occult blood test, flexible sigmoidoscopy, colonoscopy and computed tomography (CT) colonography. The latter has been officially advocated in the American guidelines [16]. Also the molecular screening of CRC seems to be a promising option with numerous possible markers, although it still requires much more research [17]. Endoscopy is favored, being both diagnostic and potentially therapeutic. The distal $60 \mathrm{~cm}$ of the colon remains within the range of flexible sigmoidoscopy. The proved reduction of CRC related mortality in FSS based screening programs amounts to $30-40 \%$ [18]. Colonoscopy enables full length bowel inspection, being in some ways superior to all methods of limited range. It must be remembered however that the tolerance and acceptance of this method are disputable. It remains to be de- 
Table III. Anatomical distribution of advanced neoplastic lesions among patients

\begin{tabular}{|c|c|c|c|}
\hline Anatomical location & $\begin{array}{l}\text { Total number } \\
\text { of patients }\end{array}$ & $\begin{array}{l}\text { Number of patients with } \\
\text { cancer }(\mathrm{Ca})\end{array}$ & $\begin{array}{l}\text { Number of patients with } \\
\text { advanced adenoma (AA) }\end{array}$ \\
\hline Cecum & 32 & $\begin{array}{c}1: \\
1 \text { with } 1 \mathrm{Ca}\end{array}$ & $\begin{array}{c}31: \\
30 \text { with } 1 \mathrm{AA} \\
1 \text { with } 2 \mathrm{AA}\end{array}$ \\
\hline Ascending colon & $45^{*}$ & $\begin{array}{c}\text { 6: } \\
6 \text { with } 1 \mathrm{Ca}^{*}\end{array}$ & $\begin{array}{c}40: \\
35 \text { with } 1 \text { AA } \\
4 \text { with } 2 \text { AA } \\
1 \text { with } 4 \text { AA }\end{array}$ \\
\hline Hepatic flexure & 17 & $\begin{array}{c}1: \\
1 \text { with } 1 \mathrm{Ca}\end{array}$ & $\begin{array}{c}\text { 16: } \\
16 \text { with } 1 \text { AA }\end{array}$ \\
\hline Transverse colon & 41 & $\begin{array}{c}\text { 2: } \\
2 \text { with } 1 \mathrm{Ca}\end{array}$ & $\begin{array}{c}39: \\
38 \text { with } 1 \text { AA } \\
1 \text { with } 2 \mathrm{AA}\end{array}$ \\
\hline Lienal flexure & 5 & $\begin{array}{c}1: \\
1 \text { with } 1 \mathrm{Ca}\end{array}$ & $\begin{array}{c}\text { 4: } \\
4 \text { with } 1 \mathrm{AA}\end{array}$ \\
\hline Descending colon & 36 & $\begin{array}{c}\text { 3: } \\
3 \text { with } 1 \mathrm{Ca}\end{array}$ & $\begin{array}{c}33: \\
32 \text { with } 1 \text { AA } \\
1 \text { with } 2 \text { AA }\end{array}$ \\
\hline Sigmoid colon & $214^{* *}$ & $\begin{array}{c}\text { 20: } \\
20 \text { with } 1 \mathrm{Ca}^{* *}\end{array}$ & $\begin{array}{c}195: \\
184 \text { with } 1 \text { AA } \\
9 \text { with } 2 \text { AA } \\
1 \text { with } 3 \text { AA } \\
1 \text { with } 4 \text { AA }\end{array}$ \\
\hline Rectum & 115 & $\begin{array}{c}\text { 19: } \\
19 \text { with } 1 \mathrm{Ca}\end{array}$ & $\begin{array}{c}96: \\
86 \text { with } 1 \text { AA } \\
10 \text { with } 2 \text { AA }\end{array}$ \\
\hline
\end{tabular}

Ca-carcinoma, AA - advanced adenoma. The values of 133 (167) patients with proximal advanced neoplasia do not strictly correspond to the sum of values in the appropriate anatomical locations due to the coexistence of lesions in different anatomical locations (see Results). *In 5 patients Ca was found as a single lesion, in 1 patient Ca coexisted with four AA. The total number of patients with advanced neoplastic lesion(s) in the cecum is 45. " In 19 patients Ca was a single lesion, in 1 patient Ca coexisted with 2 AA in this location. The total number of patients with advanced neoplastic lesion(s) in the sigmoid colon was 214

Table IV. Risk factors for proximal advanced neoplasia

\begin{tabular}{|lcccccc|}
\hline \multirow{2}{*}{ Parameter } & \multicolumn{3}{c}{$\mathbf{1}^{\text {st }}$ definition of proximality } & \multicolumn{3}{c|}{$2^{\text {nd }}$ definition of proximality } \\
\cline { 2 - 7 } & OR & $95 \% \mathrm{Cl}$ & Value of $p$ & OR & $95 \% \mathrm{Cl}$ & Value of $p$ \\
\hline Gender (M vs. F) & 1.94 & $1.31-2.87$ & 0.001 & 1.69 & $1.20-2.40$ & 0.003 \\
\hline \begin{tabular}{l} 
Age category [years]: \\
\hline$\leq 45$
\end{tabular} & & & $>0.1$ & & $>0.1$ \\
\hline$\leq 50$ & 6.76 & $0.90-50.79$ & 0.06 & 3.86 & $0.90-16.51$ & 0.07 \\
\hline$\leq 55$ & 5.79 & $0.77-43.72$ & 0.09 & 3.48 & $0.91-14.94$ & 0.09 \\
\hline$\leq 60$ & 1.05 & $0.95-1.17$ & 0.09 & & & $>0.1$ \\
\hline Family history & & & & & & $>0.1$ \\
\hline MADL: & & & $>0.1$ & & & $>0.1$ \\
\hline Distal HP & & & $>0.1$ & & & $>0.1$ \\
\hline Distal non-advanced adenoma & & & & & \\
\hline Distal advanced neoplasia & 3.58 & $2.00-6.43$ & $<0.0001$ & 3.41 & $1.95-5.96$ & $<0.0001$ \\
\hline
\end{tabular}

Cl - confidence interval, OR - odds ratio, MADL - most advanced distal lesion

cided then whether the advantages of FSS may overweigh the risk of not detecting the proximal lesions.
Epithelial lesions of the large bowel develop as the result of genetic and environmental interactions and may develop synchronously. Therefore 
it is debated whether the existence of proximal lesions can be predicted on the basis of distal findings. Distribution of epithelial polyps in symptomatic and asymptomatic populations was investigated and distal-proximal correlations have been displayed. Several authors have proved the value of distal lesions in predicting synchronous proximal neoplasia. Among considered risk factors of proximal neoplasia are also family history, age and gender. If any combination of anticipated factors could serve as a reliable predictor, it would possibly help to optimize colorectal screening.

Atkin et al. suggested that baseline FSS-detected adenomas can predict the risk of CRC development [19]. Presence of small (less than $1 \mathrm{~cm}$ ) adenomas has not been confirmed as significant by them. Existing data however are not coherent. Even smaller lesions were considered relevant in some papers. From the 1980s they were thought to be markers of neoplastic lesions in both parts of the large bowel, indicating the necessity of CS [20, 21]. Others regarded the risk of advanced neoplastic lesions as negligible, not requiring subsequent CS. According to Zarchy and Ershoff, people with small distal tubular adenoma are at only $1 \%$ risk of synchronous advanced proximal adenoma [22]. Distal advanced adenomas are associated with over $10 \%$ frequency of proximal advanced neoplasia. According to others, not the size but merely occurrence of adenomas defines the risk. Read et al. reported the existence of proximal adenomas in $29 \%$ of patients with distal adenomas of less than $5 \mathrm{~mm}, 29 \%$ with adenomas of 6-9 $\mathrm{mm}$, and in $57 \%$ of patients with advanced distal adenomas [23]. Wallace in a prospective cohort study found that the number of small adenomas may indicate higher risk, while a single distal small tubular adenoma is not significant [24].

Hyperplastic polyps' value as predictors of advanced proximal neoplasia has also been investigated. Lin et al. performed a meta-analysis of 21 studies, concluding that in asymptomatic patients presence of distal hyperplastic polyps was not associated with increased risk of either non-advanced or advanced neoplasia in the proximal coIon [25].

To consider the predictive value of major proposed factors, we used a multivariate model, incorporating age, gender, family history and most advanced distal lesions (categorized into hyperplastic polyps, non-advanced adenomas and advanced neoplastic lesion categories). In our study male gender was associated with twice the risk of proximal advanced neoplasia compared to females, which is in line with previous observations. Nguyen et al. in a meta-analysis including about one million asymptomatic screened patients observed the relative risk associated with male gen- der to be 1.83 (95\% Cl: 1.69-1.97) compared to females, regardless of the age category [26]. Our results do not support the postulated association between age and proximal advanced neoplasia [27]. Although in our study there was a tendency in older subgroups, it did not reach the level of statistical significance. Family history was not of value in predicting advanced proximal neoplasia.

Unequivocal predictive value was proved for the presence of distal advanced neoplasia. It was associated with 3.5 times higher risk of synchronous proximal advanced neoplasia (OR 3.58 and 3.41 for the first and second definition of proximality, respectively), and was highly significant.

There are some limitations of our study. Doubts concerning recruitment policies in screening programs always exist. Some of the patients may have not been totally asymptomatic, which may be a potential source of bias. The precise reporting of the anatomical locations in the colon also seems to be uncertain, which is however a usual restriction of the endoscopic evaluation in such studies. Furthermore, we do not directly compare different screening endoscopic methods, but rather concentrate on identification and appraisal of certain predictive factors. In the light of our results males and people with distal advanced neoplastic lesions seem to constitute a subgroup of asymptomatic participants who would especially benefit from the full colonoscopy strategy. It remains to be determined then whether the full colonoscopy-based screening is necessary in all asymptomatic participants, or in certain subgroups only (identified in our study), without the significant risk of a negative impact on screening effectiveness and subsequent cancer-related mortality.

In conclusion, the results may indicate some limitations of flexible sigmoidoscopy in the colorectal screening settings, at least in men and people with distal advanced neoplastic lesions. Thus, our study contributes to the ongoing debate regarding endoscopic screening strategies.

\section{References}

1. Klimczak A, Kempińska-Mirosławska B, Mik M, Dziki L, Dziki A. Incidence of colorectal cancer in Poland in 1999-2008. Arch Med Sci 2011; 7: 673-8.

2. Świątkowski M, Meder A, Sobczyński L, et al. Adenomas detected during screening colonoscopies in the years 2000-2009. Prz Gastroenterol 2012; 7: 299-305.

3. Konishi F, Morson BC. Pathology of colorectal adenomas: a colonoscopic survey. J Clin Pathol 1982; 35: 830-41.

4. Atkin WS, Edwards R, Kralj-Hans I, et al. UK Flexible Sigmoidoscopy Trial Investigators. Once-only flexible sigmoidoscopy screening in prevention of colorectal cancer: a multicentre randomised controlled trial. Lancet 2010; 375: 1624-33.

5. Brenner H, Chang-Claude J, Seiler CM, Rickert A, Hoffmeister M. Protection from colorectal cancer after colo- 
noscopy: a population-based, case-control study. Ann Intern Med 2011; 154: 22-30.

6. Winawer S, Fletcher R, Rex D, et al. Gastrointestinal Consortium Panel. Colorectal cancer screening and surveillance: Clinical guidelines and rationale - update based on new evidence. Gastroenterology 2003; 124: 544-60.

7. Frazier AL, Colditz GA, Fuchs CS, Kuntz KM. Cost-effec tiveness of screening for colorectal cancer in the general population. JAMA 2000; 284: 1954-61.

8. U.S. Preventive Services Task Force. Screening for colorectal cancer: US Preventive Services Task Force recommendation statement. Ann Intern Med 2008; 149: 627-37.

9. Podolsky DK. Going the distance - the case for true colorectal-cancer screening. N Engl J Med 2000; 343: 207-8.

10. Rabeneck L, Davila JA, El-Serag HB. Is there a true "shift" to the right colon in the incidence of colorectal cancer? Am J Gastroenterol 2003; 98: 1400-9.

11. Kiedrowski M, Mróz A, Kamiński MF, et al. Proximal shift of advanced adenomas in the large bowel - does it really exist? Pol Arch Med Wewn 2012; 122: 195-9.

12. Imperiale TF, Wagner DR, Lin CY, Larkin GN, Rogge JD, Ransohoff DF. Risk of advanced proximal neoplasms in asymptomatic adults according to the distal colorectal findings. N Engl J Med 2000; 343: 169-74.

13. Imperiale TF, Wagner DR, Lin CY, Larkin GN, Rogge JD, Ransohoff DF. Using risk for advanced proximal colonic neoplasia to tailor endoscopic screening for colorectal cancer. Ann Intern Med 2003; 139: 959-65.

14. Principles of the screening program published on the website of the Polish Ministry of Health. http://www. mz.gov.pl/wwwmz/index? $\mathrm{mr}=\mathrm{m} 2111 \& \mathrm{~ms}=416 \& \mathrm{~m}-$ $l=p l \& m i=0 \& m x=0 \& m t=\& m y=0 \& m a=05232$ Accessed April 17, 2013.

15. Tumours of the colon and rectum. In: Hamilton SR, Aaltonen LA, eds. World Health Organization Classification of Tumours. Pathology and Genetics of Tumours of the Digestive System. Lyon, France: IARC Press; 2000: 104.

16. Levin B, Lieberman DA, McFarland B, et al.; American Cancer Society Colorectal Cancer Advisory Group; US Multi-Society Task Force; American College of Radiology Colon Cancer Committee. Screening and surveillance for the early detection of colorectal cancer and adenomatous polyps, 2008: a joint guideline from the American Cancer Society, the US Multi-Society Task Force on Colorectal Cancer, and the American College of Radiology. CA Cancer J Clin 2008; 58: 130-60.

17. Żelazowski MJ, Bednarek AK. The state of contemporary molecular diagnostics of colorectal cancer. Contemp Onkol (Poznan) 2011; 15: 229-33.

18. Selby JV, Friedman GD, Quesenberry CP, Weiss NS. A case-control study of screening sigmoidoscopy and mortality from colorectal cancer. N Engl J Med 1992; 326: 653-7.

19. Atkin W, Borson B, Cusick J. Long-term risk of colorectal cancer after excision of rectosigmoid adenomas. $\mathrm{N}$ Engl J Med 1992; 326: 658-62.

20. Achkar E, Carey W. Small polyps found during fiberoptic sigmoidoscopy in asymptomatic patients. Ann Intern Med 1988; 109: 880-3.

21. Opelka FG, Timmcke AE, Gathright JB Jr, Ray JE, Hicks TC. Diminutive colonic polyps: an indication for colonoscopy. Dis Colon Rectum 1992; 35: 178-81.

22. Zarchy TM, Ershoff D. Do characteristics of adenomas on flexible sigmoidoscopy predict advanced lesions on baseline colonoscopy? Gastroenterology 1994; 106: 1501-4.
23. Read TE, Read JD, Butterly LF. Importance of adenomas $5 \mathrm{~mm}$ or less that are detected by sigmoidoscopy. N Engl J Med 1997; 336: 8-12.

24. Wallace MB, Kemp JA, Trnka YM, Donovan JM, Farraye FA. Is colonoscopy indicated for small adenomas found by screening flexible sigmoidoscopy? Ann Intern Med 1998; 129: 273-8.

25. Lin OS, Gerson LB, Soon MS, Schembre DB, Kozarek RA. Risk of proximal colon neoplasia with distal hyperplastic polyps: a meta-analysis. Arch Intern Med 2005; 165: 382-90.

26. Nguyen SP, Bent S, Chen YH, Terdiman JP. Gender as a risk factor for advanced neoplasia and colorectal cancer: a systematic review and meta-analysis. Clin Gastroenterol Hepatol 2009; 7: 676-81.

27. Boursi B, Halak A, Umansky M, Galzan L, Guzner-Gur H, Arber N. Colonoscopic screening of an average-risk population for colorectal neoplasia. Endoscopy 2009; 41: 516-21. 